\title{
SPLINE FINITE DIFFERENCE METHOD FOR A CLASS OF BOUNDARY-VALUE PROBLEMS
}

\author{
I. Khan, T AzIz, A. Khan, S.M. El-SAYed
}

\begin{abstract}
In this paper, we consider spline finite difference method based on uniform mesh for solving a class of two-point boundary value problems of the form

$$
\begin{gathered}
e^{-\alpha x}\left(e^{\alpha x} u^{\prime}\right)^{\prime}=f(x, u), a \leq x \leq b, \\
u(a)=A, u(b)=B
\end{gathered}
$$

is presented. Three-point finite difference method using splines is obtained for the solution. We show that the resulting method provides second order convergence. Two test examples are solved to demonstrate the efficiency of the method.
\end{abstract}

\footnotetext{
Received 13-06-2007, Accepted 14-05-2008.

2000 Mathematics Subject Classification: 65L10, CR:G1.7

Key words and Phrases: Two-point boundary value problems, finite difference methods, spline solution, continuity condition.

I. Khan: Department of Applied Mathematics, Faculty of Eng. \& Technology, A.M.U. Aligarh-202002, India. E-mail: isk@yahoo.co.in

T. Aziz: Department of Applied Mathematics, Faculty of Eng. \& Technology, A.M.U. Aligarh-202002, India.

A. Khan: Department of Mathematics, A.M.U. Aligarh-202002, India

S.M. El-Sayed: Department of Mathematics, Faculty of Sciences, Benha University, Benha-13518, Egypt.

E-mail: ms4elsayed@yahoo.com
} 